\title{
Maternal Nutrition in Early Pregnancy Effects Placental Development
}

\author{
J. J. Babu Geddam, Radhakrishna K.V., Ramalaxmi B.A., Balakrishna N., Qadri S.S.Y.H., Sesikeran B. \\ National Institute of Nutrition, Indian Council of Medical Research, Jamai Osmania (P.O), Hyderbad-500 604, India.
}

\section{A B STRACT}

Background: Recent experimental and clinical studies have identified maternal malnutrition at conception or during early period of gestation as an important factor determining the fetal growth as early as the first trimester of pregnancy. Placenta is a transient embryonic organ of communication between mother and fetus during pregnancy and is the only source of nutrient transfer to the fetus. Hence its proper development is essential for fetal growth and development right from embryonic stages of development. Objective: To assess and compare the placental morphology by measuring the villous structure, vascular endothelial growth factor (VEGF) and placental growth factor (PLGF) expression from placental tissue at 7-10 weeks of gestation of low socioeconomic status (LSES) and high socioeconomic status (HSES) groups, in relation to their nutritional status. Material: Placental tissue samples obtained at 7-10 weeks of gestation from healthy women undergoing medical termination of pregnancy constituted the study material. Methodology: A total of 99 placental tissue samples, 59 from LSES and 40 from HSES groups were examined to assess the morphology of placental villi and also stained for VEGF and PLGF expression. Nutritional status of the subjects was measured by recording weight, height and hemoglobin, serum retinol, serum zinc and folic acid using standard methods. Results: Women belonging to both the income groups were of comparable to age. Body Mass Index (BMI) was significantly lower $(P<0.001)$ in the LSES group. Hemoglobin concentrations were significantly $(P<0.05)$ more in HSES groups when compared to LSES group. Hematoxylin-eosin stained placental tissue sections showed that number of floating villi $(P<0.001)$, villous vascular density $(P<0.001)$, central disposition of blood vessels $(P<0.05)$ and syncytial sprouts $(\mathrm{SS})$ $(P<0.05)$ were significantly higher in the LSES group. While the intensity of staining for VEGF was higher, the decidual vascular density was significantly $(P<0.05)$ lower in the LSES group. Serum retinol, folic acid and zinc of both groups were within normal range and comparable. Conclusions: The significant disparity in placental morphology observed in this study between LSES and HSES groups at a comparable gestational period is interesting and suggestive of predominant hypoxemic placental development under the stress of under nutrition.

Key words: Maternal Nutrition, Placenta and Growth factors.

\section{INTRODUCTION}

Low birth weight due to intrauterine growth retardation (IUGR) constitutes a major public health problem in most developing countries including India. (de Onis M, 1998). Fetuses suffering from growth impairment face an increased risk of intrauterine complications as well as negative, short and long term health outcomes postnatally. ${ }^{2}$ (Villar J, 1990).

Address for correspondence:

Tel No.040-27197377; E-Mail: geddambabuj@yahoo.com;

Fax: $91-40-27019074$.

Emails: Radhakrishna K.V. - vijk@yahoo.com; Ramalaxmi B.A. barl1248@yahoo.co.in; Balakrishna N.-dr_nbk@yahoo.com;

Qadri S.S.Y.H. - ssyhq@yahoo.com;

Sesikeran B.-sesikeran@gmail.com

DOI: 10.5530/ijmedph.2.2011.6
The IUGR is a crucial element in the intergenerational vicious cycle of poverty, growth failure, infectious diseases and malnutrition (de Onis M, 1998). Recent clinical and experimental studies have identified maternal under nutrition at conception or gestation at an early age as an important factor restricting fetal growth as early as the first trimester of pregnancy.

Body Mass Index (BMI) is a simple but objective anthropometric indicator of the nutritional status of the adult population and seems to be closely related to their food consumption levels (Nadamuni Naidu A, 1994). A low BMI status, indicative of Chronic Energy Deficiency, is a particularly important aspect of the nutritional risk of women in a community during the reproductive years (Kusin JA, 1994). Mothers from the low socioeconomic strata had infants with low birth weights and birth weights were linearly correlated with both maternal weights and heights (Kapur S.et al, 1971). 
There is a large body of evidence showing that the anatomy, physiology, endocrinology and many other biological functions of the first trimester placenta are different from the placenta of the second and third trimesterr (Rodesch 1992, Jauniaux E 1994, Meuris S 1995, Genbacev O 1996).

Extra villous trophoblast (EVT) cells of developing placenta proliferate and migrate out of chorionic villi and invade the uterine endometerium and its vasculature in order to establish a proper exchange of key molecules between the mother and the fetus. Proliferation, migration and invasion of EVT cells are regulated by paracrine, autocrine and justacrine mechanisms involving a variety of growth and regulatory factors within the micro environment (Graham $\mathrm{CH}$ 1992, Lala PK 1996). Normal chorionic villous vascularization is essential for the undisturbed development of pregnancy to allow optimal maternal fetal exchange of oxygen and nutrition between the intervillous maternal blood and the villi at the functional transfer site (Meegdes BH 1988). In the early placental development, more number of mature villi with predominant peripheral vessels is needed to facilitate better materno-fetal transfer of nutrients (te Velde EA 1997). In complicated pregnancies, early uteroplacental blood flow hemodynamics is significantly different than in normal pregnancies (Jaffe R 1992, Jauniaux E 1994, Kurjak A 1991). This suggests that establishment of the inter villous circulation must follow a well defined pattern to enable the early placenta not only to implant but also protect the developing embryo and fetus from various mechanical and biochemical stresses during embryogenesis and organogenesis (Hustin J 1995). Early embryonic development occurs in predominantly hypoxic environment and hypoxia is thought to restrict trophoblastic invasion in early pregnancy. Placenta is a transient embryonic organ of communication between the mother and fetus during pregnancy and establishes functional connections essential for nutrient transfer which are critical for embroyonic survival (James 1994).

Vascular endothelial growth factor (VEGF) and placental growth factor (PLGF) are two related protein members of the endothelial growth factor family with potent angiogenic and mitogenic growth activities that result in enhanced permeability of vascular endothelium. VEGF is a dimeric glycoprotein that is produced and secreted in vivo by a wide variety of cells (Sharkey AM 1996, Baker PN 1995, Kupferminc MJ 1997, Lyall F 1997). VEGF in human placenta is in the villous cytotrophoblast in the first trimester and the synctiotrophoblast in term placentas (Cheung CY 1997, Torry DS 1997, Lyall F 1997). Immunocytochemical studies show strong staining for VEGF on cytotrophoblast cells and extra villous trophoblast cells in early pregnancy. Growth factors are critical during the initial cytotrophoblastic invasion which occurs during early pregnancy (Anthony FW 1997). Villous trophoblastic sprouts are believed to represent sites of production of new villi from existing villi (Benersche K 1990).

To understand the role of maternal nutrition in early pregnancy, a study was planned to assess the placental morphology by measuring villous structure from placental samples obtained from medical termination of pregnancy (MTP) at 7-10 weeks of gestation. VEGF and PLGF expressions were also studied in the same samples. Villous structure vasculature and growth factor expression were compared in relation to maternal nutrition status from HSES and LSES groups.

Maternal nutritional status is very important in the early development of embryo. Placenta gets its supply through the decidual vessels located in the decidua basalis, where the implantation occurs. Placenta being the main nutrient supplier to the growing embryo, the study mainly aimed at looking for any possible changes in early placental development as measured by villous structure, number, vessel formation, sprout formation etc.

\section{SUBJECTS AND METHODS}

The study was done using the placental tissues collected from healthy women undergoing medical termination of unwanted pregnancy in the first trimester, after obtaining the clearance of Ethical Committee as well as the written informed consent from the subjects. Women with a history of venereal diseases, human immunodeficiency virus infection (HIV), smoking, prolonged hyperemesis, chronic bacterial infections, congenital malformation in previous deliveries and those with previous history of abortions were excluded. A total of 227 placental samples were collected between 5 to 10 weeks of gestation, assessed by the date of last menstrual period. Of these, 127 samples of LSES group were obtained from the Government Hospital (Niloufer Hospital, Hyderabad) and 100 samples of HSES group from Swapna Nursing Home, Hyderabad.

\section{Anthropometric measurements}

Anthropometric measures of height and weight were determined in the subjects using standard methods and equipment (Jelliffe DB 1966).

\section{MORPHOMETRY}

Placental tissue was fixed in 10\% buffered neutral formalin. The entire material was sampled and processed paraffin blocks were cut to obtain $3 \mathrm{~mm}$ serial sections. Sections were stained with haemotoxylin and eosin. Every fifth section was taken for the study. Slides were examined by light microscopy and those slides showing good number of villi 
and implantation site with anchoring villi were selected for scoring. Ten fields identified under low power and selected randomly were examined in each slide. The scoring was done under medium power $40 \mathrm{x}$. The scoring was repeated in $20 \%$ of randomly selected slides by two scientists for reliability and reproducibility.

Mean number of villi, percentage of villi with blood vessels, decidual vascular density, and percentage of villi with syncytial sprouts and disposition of blood vessels like central and peripheral were scored (Fig. 1a).

The scores in these samples varied with the gestational age but were similar in 7 to 10 weeks. Therefore, 7 to 10 weeks gestational period was taken as cut off point for further analysis. A total of 99 samples from both groups were stained with heamotoxylin and eosin for morphological characters.

\section{IMIMUNOHISTOCHEMISTRY}

VEGF and PLGF staining was done using Santa Cruz kits (USA). After selecting the slides having implantation site, immunohistochemistry studies were carried out for VEGF (82) and PLGF (52) expression. Briefly, the staining procedure for VEGF includes deparaffinization using xylene and hydration was achieved using descending grades of alcohol and distilled water. Sections were transferred to $0.1 \mathrm{M}$ citrate buffer and autoclaved at $120^{\circ} \mathrm{C}$ for 5 minutes for antigen retrieval. Slides were cooled in buffer for 20 to 30 minutes and washed with 1.1M Phosphate Buffered Saline (PBS). Excessive PBS was drained out and endogenous peroxidase activity was blocked for 30 minutes. Sections were again drained and washed with PBS. Sections were layered with blocking antibody goat serum for 15 minutes. Excessive serum was blotted. Then sections were layered with primary antibody (Rabbit polyclonal IgG $5 \mathrm{ml}$ of $5 \mu \mathrm{g} / \mathrm{ml}$ concentration) and incubated for 2 hours at room temperature. Slides were washed with PBS, drained and wiped.

Biotinylated $2^{\text {nd }}$ antibody was applied for 30 minutes and washed again with PBS. Slides were drained and wiped;

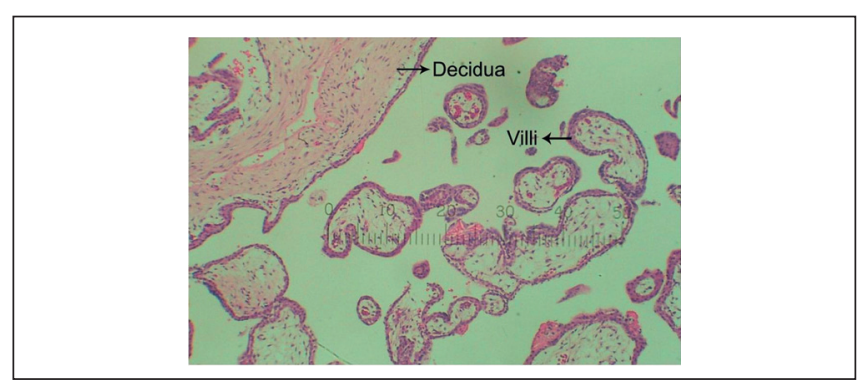

Figure 1a: Villi and decidua with H \& E staining (125x)
Avidin biotin peroxidase reagent was applied for 30 minutes and washed with PBS. Di-amino benzidine tetrahydro chloride (DAB) solution was applied for 7 minutes and the slides were dipped in distilled water for 5 minutes. Sections were counterstained with Meyer's hemotoxylin for 5 minutes and dipped in distilled water for 6 minutes. Dehydration was accomplished by dipping the slides in $50 \%, 70 \%$ and $95 \%$ absolute alcohol for five minutes each. Slides were again dipped in 1:1 xylene and alcohol and xylene for five minutes each and were mounted with DPX mountant (Fig. 2b).

PLGF staining (Fig. 3b) was done using donkey serum as serum block and affinity purified goat polyclonal antibody raised against a peptide mapping at the carboxy terminus of placental growth factor (PLGF) of human origin was used as primary antibody. The remaining steps were similar to VEGF staining.

\section{Scoring method}

After Immunohistochemistry staining, four peripheral and one central fields of each slide were scored to cover 100 villi from each sample (Fig. 4b). Based on the intensity of the staining the grading was done on semi-quantified method using a 3 point Grade scale: Cells with no staining to minimal staining - Grade 1, moderate staining - Grade 2 and deep staining - Grade 3. After scoring all the cells, hundred villi are expressed as percentage of cells with different grades of staining.

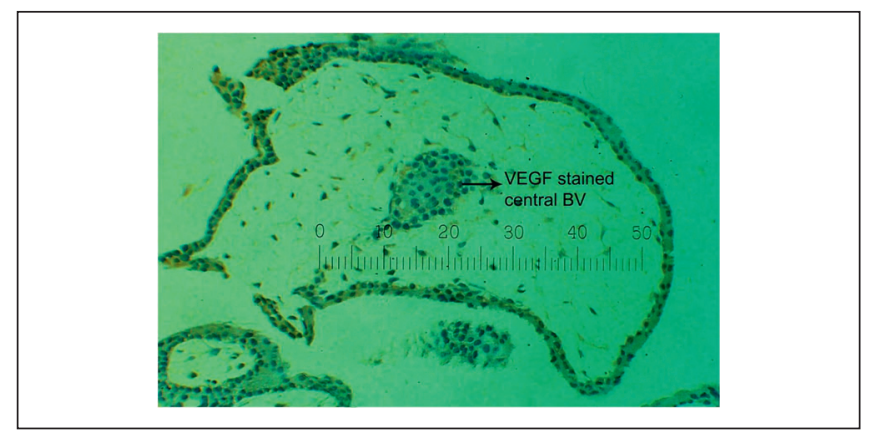

Figure 2b: Villi with blood vessels showing VEGF staining (325 xs)

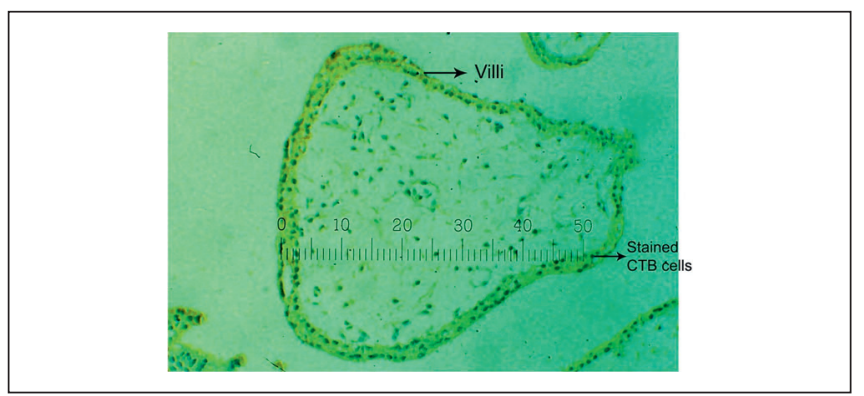

Figure 3b: Villi with PLGF staining (325x) 


\section{Positive and Negative controls}

Thyroid tissue sample was taken as positive (Figs. 5 and 6) and neurofibroma as a negative control (Fig. 7) for immunohistochemistry staining.

\section{Biochemical parameters}

Five $\mathrm{ml}$ of venous blood was collected from each subject before they underwent medical termination of pregnancy. Hemoglobin (cyanmethemoglobin method) (INACG 1985), serums zinc (atomic absorption spectrophotometry) (Taylor method, folic acid (radioimmunoassay) and Vitamin A (HPLC) were determined (Bieri G. et al. 1979).

\section{Statistical methods}

SPSS Windows Version 11.5 was used for data analysis. The mean values of maternal characters, placental morphology and growth factors between two socioeconomic groups were compared using student' $t$ ' test. Confidence intervals were also calculated for each parameter. ANCOVA (Analysis of Co-variance) was used for adjusted mean values and were

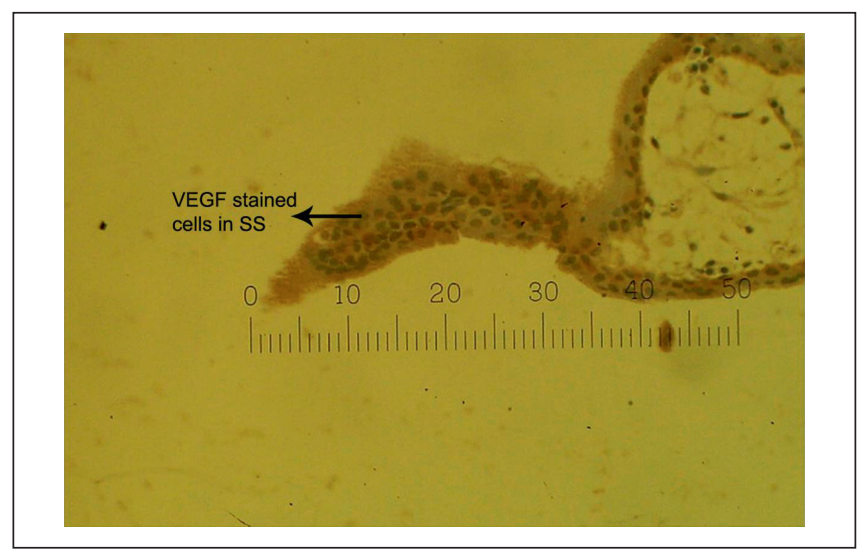

Figure 4b: Positive staining of VEGF showing blood vessel and SS $(325 x)$

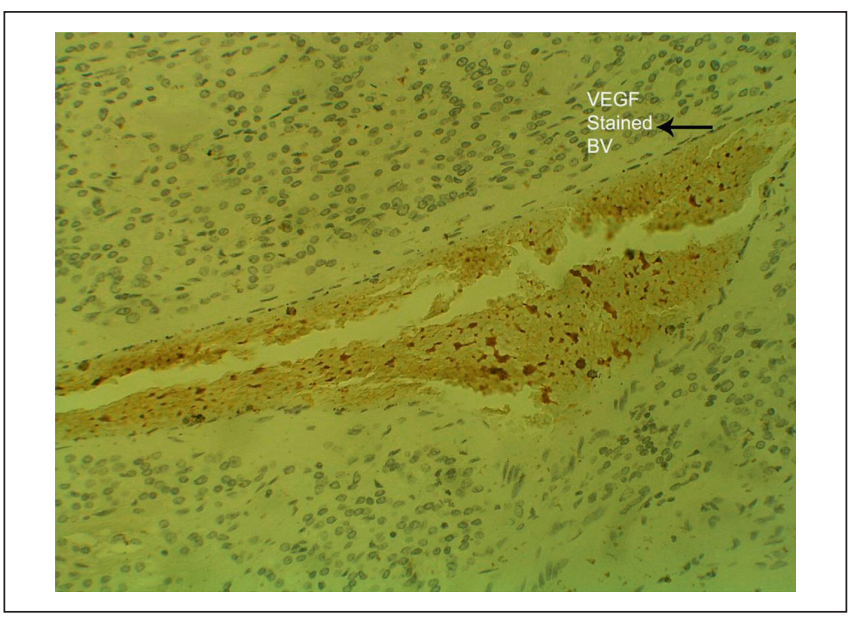

Figure 5b: Thyroid tissue for positive control of VEGF showing blood vessel (325x) compared after controlling BMI, parity and hemoglobin values between socio-economic groups. Relationship was measured through correlation coefficient. Statistical significance was considered at a $P$ value $<0.05$.

As it is very difficult to get the exact peri-conceptional nutritional status either macro or micro, it was decided to take the nutritional status at 7-10 weeks of gestation as representative/proxy of peri-conceptional nutritional status, since maternal diet or body compositional changes do not alter much in early pregnancy (Durnin JV, 1987).

\section{RESULTS}

Profiles of the two socio-economic groups are given in Table 1. Mean and SE of women belonging to LSES $(26.5 \pm 0.58)$ and HSES $(27.5 \pm 0.82)$ groups were of comparable mean age $(P>0.05)$ (Table 2). Women of LSES group $(1.9 \pm 0.15)$ had significantly more parity

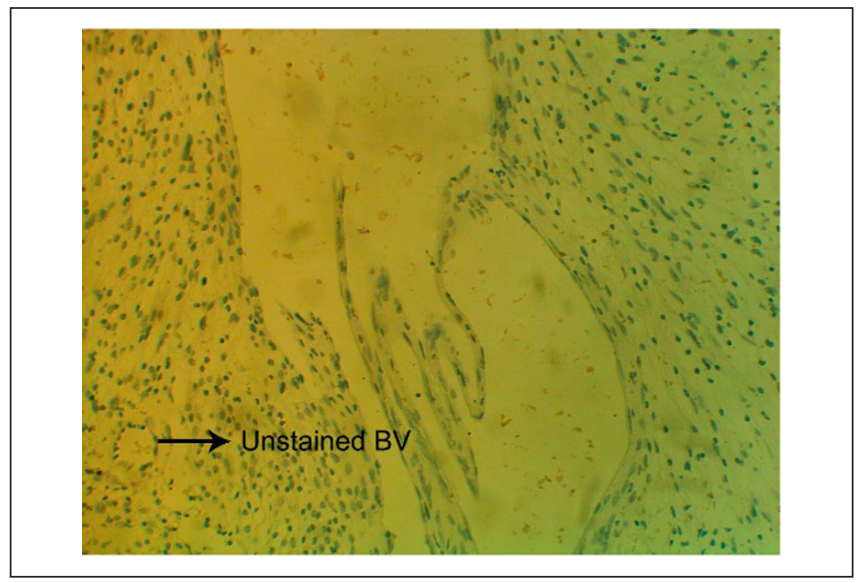

Figure 6b: Thyroid tissue without a primary antibody for negative control of VEGF showing blood vessel (325x)

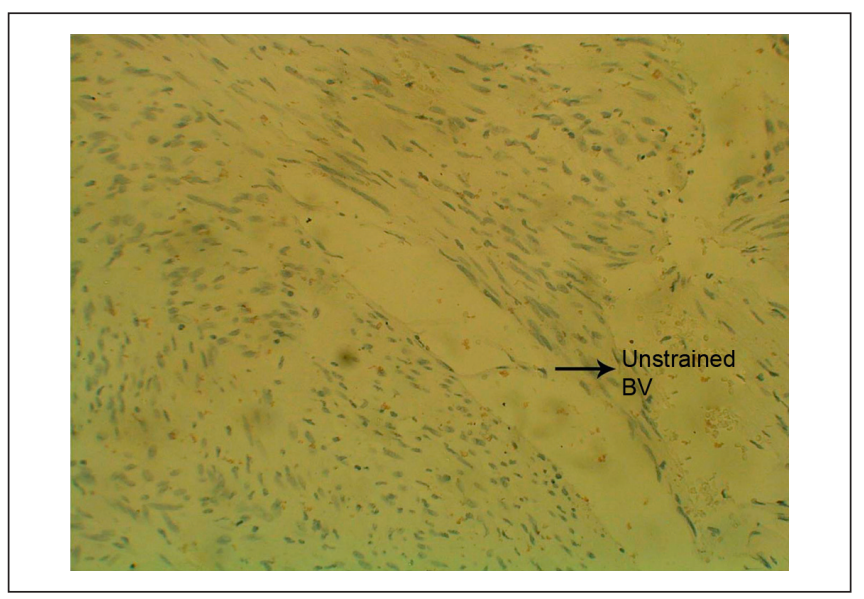

Figure 7a: Negative control for VEGF showing of neurofibroma tissue showing blood vessel (125x) 
$(P<0.05)$, lower mean body weight $(45.6 \pm 1.17)(P<0.001)$ and low mean height $(151.7 \pm 1.83)(P<0.05)$ when compared to HSES group. Mean hemoglobin concentrations were significantly $(P<0.05)$ more in HSES groups $(10.5 \pm$ $0.15)$ when compared to LSES group $(9.82 \pm 0.19)$. Vitamin $\mathrm{A}$, folic acid and zinc micro nutrient concentrations of both groups were with in normal range and comparable.

Haemotoxylin stained slides (Table 3) showed that mean number of floating villi (113.2) $(P<0.05)$, villous vascular density $(62.0)(P<0.001)$, central disposition of the blood vessels $(47.5)$ were significantly higher $(P<0.001)$ in the LSES group. The mean syncytial sprouts were also significantly higher $(P<0.05)$ in LSES group (41.7) when compared to HSES group (31.2). The variables were significant even after controlling BMI, parity and hemoglobin between two socio-economic groups except for floating villi.

Decidual vascular density was significantly $(\phi<0.01)$ higher in HSES women (8.8 Vs 6.2, CI 6.7, 10.9 and 5.0, 7.3) compared to LSES group. Even after controlling for BMI,

\begin{tabular}{lccc} 
Table 1: Study profile & & & \\
\hline \multicolumn{1}{c}{ Groups } & LSES & HSES & Total \\
\hline No. of samples Collected & 127 & 100 & 227 \\
H\&E stained samples & 59 & 40 & 99 \\
Immunohistochemistry For VEGF & 46 & 36 & 82 \\
Immunohistochemistry For PLGF & 26 & 26 & 52 \\
Bio chemical parameters & 59 & 40 & 99 \\
\hline
\end{tabular}

$\mathrm{HB}$, and parity it was significantly different (9.9 Vs 5.3, $p<0.01)$.

BMI negatively correlated with villous blood vessels and central disposition of vessels $(P<0.05)(r=-0.203$ and -0.28 respectively), whereas parity positively correlated with number of villi $(P<0.05, r=0.208)$.

In the LSES group, mean percentage of floating villi with positive staining (76) for VEGF was significantly $(P<0.05)$ more when compared to HSES group (72) with Mahn Whitney 'W' test. But expression of VEGF in cytotrophoblast and in blood vessels was comparable in both groups (Table 4). The mean values of percentage of villi with positive staining was higher in LSES but not statistically significant $(P=0.057)$ after eliminating the parity.

The intensity of staining for VEGF was higher in LSEG. Floating villi, CTB expression, and staining intensity pattern for PLGF were comparable between the two socioeconomic groups.

\section{DISCUSSION}

There is substantial evidence to show that poor maternal nutrition status at conception and inadequate maternal nutrition during pre-pregnancy can result in IUGR. Maternal anthropometric indicators have been useful for screening women at nutritional risk and predicting unfavorable infant outcomes relating to pregnancy, LBW, perinatal, neonatal

\section{Table 2: Baseline characters of the subjects}

\begin{tabular}{lcc}
\hline \multicolumn{1}{c}{ Parameters } & Low socioeconomic status $(\boldsymbol{n}=\mathbf{5 9})$ & High socioeconomic status $(\boldsymbol{n}=\mathbf{4 0})$ \\
\hline Age $(\mathrm{yrs})$ & $26.5(25.3,27.7)$ & $27.5(25.9,29.1)$ \\
Para & $1.9^{*}(1.6,2.3)$ & $1.4(1.2,1.6)$ \\
Weight $(\mathrm{kg})$ & $45.6^{* *}(43.3,47.9)$ & $60.9(57.5,64.2)$ \\
Height $(\mathrm{cm})$ & $151.7^{*}(148.1,155.4)$ & $157.3(155.6,158.9)$ \\
$\mathrm{BMl}$ & $19.3^{* *}(18.5,20.2)$ & $24.6(23.5,25.8)$ \\
$\mathrm{Hb}(\mathrm{g} / \mathrm{dl})$ & $9.8^{*}(9.46,10.17)$ & $10.5(10.20,10.75)$ \\
Serum retinol $(\mu \mathrm{g} / \mathrm{dl})$ & $25.2(22.1,28.2)$ & $28.6(24.5,32.6)$ \\
Serum folic $\mathrm{acid}(\mathrm{ng} / \mathrm{dl})$ & $6.0(5.3,6.8)$ & $7.3(5.8,8.7)$ \\
Serum zinc $(\mu \mathrm{g} / \mathrm{dl})$ & $89.6(80.1,98.9)$ & $94.0(83.9,104.1)$ \\
\hline
\end{tabular}

Values are mean $(95 \% \mathrm{Cl}) ; * P<0.05 ; * * * P<0.001$

$n=$ Number of subjects.

\begin{tabular}{lcc} 
Table 3: Placental structure and morphology by maternal Socioeconomic status & \multicolumn{1}{l}{ HSES $(\boldsymbol{n}=\mathbf{4 0})$} \\
\hline Placental morphology parameters & \multicolumn{1}{l}{ LSES $(\boldsymbol{n}=\mathbf{5 9})$} & $96.9\{98.8\}^{*}(87.7,106.2)$ \\
\hline Floating villi & $113.2^{*}\{110.0\}(101.8,124.6)$ & $46.8\{46.8\}^{*}(42.4,51.1)$ \\
Villi with blood vessels & $62.0^{* * *}\{60.2\}(55.2,68.8)$ & $32.0\{32.1\}^{* *}(28.3,35.6)$ \\
Mean of center blood vessels & $47.5^{* *}\{46.5\}(42.12,52.9)$ & $31.2\{31.2\}^{*}(27.0,35.3)$ \\
Synctial sprouts & $41.7^{* *}\{41.2\}(36.6,46.1)$ & 31.2\{
\end{tabular}

Values are Mean number and each of the parameters scored from 5 areas in each sample

Figures in ( ) $95 \%$ Confidence intervals

$\{$ \} adjusted values for BMI, $\mathrm{HB}$ and parity

Significance: ${ }^{N} \mathrm{NS} ; * P<0.05 ; * * P<0.01 ; * * * P<0.001$ 


\begin{tabular}{|c|c|c|}
\hline VEGF & $\begin{array}{l}\text { LSES } \\
(46)\end{array}$ & $\begin{array}{l}\text { HSES } \\
(36)\end{array}$ \\
\hline \% Villi with positive staining & $76^{*}(73.1,78.2)$ & $72(69.2,74.1)$ \\
\hline$\%$ CTB expression & $61(59.8,63.2)$ & $62.3(60.4,64.9)$ \\
\hline $\begin{array}{l}\% \text { VEGF staining in blood } \\
\text { vessels }\end{array}$ & $60(57.5,63.1)$ & $61(57.5,64.8)$ \\
\hline $\begin{array}{l}\text { Intensity of staining } 3+ \\
\% \text { villi }\end{array}$ & $70[32]^{\star \star *}$ & $17[8]$ \\
\hline $2+$ & $22[10]$ & $41[19]$ \\
\hline $1+$ & $8[4]$ & $41[9]$ \\
\hline PLGF & (26) & (26) \\
\hline$\%$ Villi with positive staining & $74(68.7,79.8)$ & $70(66.8,73.5)$ \\
\hline \% CTB Expression & $62(59.8,64.3)$ & $60(57.2,63.5)$ \\
\hline$\%$ Intensity of staining $3+$ & $54[14]$ & $35[9]$ \\
\hline $2+$ & $35[9]$ & $38[10]$ \\
\hline $1+$ & $11[3]$ & $27[7]$ \\
\hline \multicolumn{3}{|c|}{$\begin{array}{l}\text { Values are mean }(95 \% \mathrm{Cl}) \text { of each of the parameters scored from } 5 \text { areas } \\
\text { in each sample. } \\
\text { [ ] Number of subjects studied. } \\
\text { Significance: } * P<0.05 ; * * P<0.01 ; * * * P<0.001\end{array}$} \\
\hline
\end{tabular}

infant mortality and poor infant growth (Kardjati S 1988, Krammer M 1987, Naeye RL 1979). Maternal weight or BMI has been the most sensitive predictor in relation to infant outcomes when compared with other maternal anthropometric indices (Husani MA1995). The results showed significant differences between the groups in anthropometry data and haemoglobin levels. These points to overall CED in LSES women. The low BMI in LSES women, which reflects chronic energy deficiency effects early placental and embryonic development and can also have long term effects in later pregnancy.

Among the biochemical parameters there were no significant differences between the high and low SE groups. . The levels of zinc may not change due to homeostasis, unless there is severe zinc deficiency. Though serum levels of retinol, folic acid and zinc were not different among the two groups, we do not have knowledge of their tissue levels and there are many other nutrients that are essential in the early development. In early embryonic development nourishment to embryo is through the embryotrophe, the secretions and tissue fluid surrounding the early embryo embedded in the uterine deciduas.

It is well known that early embryonic development occurs under hypoxic conditions. Our results show decreased decidual vascular density which leads to decreased nutrient supply to growing embryo in LSES and increased villi formation, syncytial sprouts density and vascular development within the villi in LSEG. From these results, one may assume that the increased syncytial sprouts, villi formation and vascular development is aimed at getting better nourishment for the embryo for future development.
The process of implantation and trophoblast invasion, which characterize early pregnancy are accompanied by major changes in uterine vasculature and by the development of the villous vasculature connecting embryo and trophoblast (Evans PW 1998). Immunocytochemical studies show strong staining for VEGF on cytotrophoblast cells in early pregnancy (Jackson MR 1994, Clark DE 1996). VEGF expression is upregulated by hypoxia (Scheweiki D 1992, Wheeler T 1995). VEGF, an angiogenic growth factor, may have several roles in pregnancy and it is likely to influence the development of new blood vessels in both embryo and trophoblast (Evans PW 1998). Blood vessels develop to satisfy the metabolic demands of the tissues which they supply and tissue oxygen status may be an important trigger which regulates VEGF production. Under these circumstances, VEGF may influence villous trophoblast cells having VEGF receptors (Charnock-Jones DS 1994). These cells have the critical function of invading the maternal decidual and sprial arterioles at the time of implantation. Hypoxia stimulates cytotrophoblast proliferation and inhibits trophoblast invasion (Genbacev O 1996). This study shows that percentage of floating villi with positive staining of VEGF and intensity of stain for VEGF was higher in the LSES.

At around 12 week's gestation, the intervillous space switches from relative hypoxia to an enhanced hyperoxemic state. In pre-eclampsia and IUGR, the uterine blood vessels do not undergo vascular transformation. Therefore, the rate of delivery of oxygenated blood to the fetus falls. This placental insufficiency has led to the notion of placental hypoxia.

Hypoxia is not only known to stimulate cell proliferation and enhance vasculogenesis but is also known to up regulate VEGF and down regulates the PLGF (Ahmed A 1997). This study indicates that there is no difference in the PLGF expression between the groups. It is well established that placental development undergoes a gradual transition from an early hypoxemic to a later hyperoxemic state. This transition has been described to commence at about 8 to 10 weeks of gestation and completed by the end of the first trimester in normal pregnancies.

The present study showed high number of floating villi with increased vasculature and large number of syncitial sprouts in the placental tissue obtained from the undernourished women. The fetus/embryo derive its nourishment from the decidual vessels. Decidual vascular density was higher in HSES group. This suggests to the possibility of relative hypoxia leading to an attempt at increasing the nutrient supply to the embryo.

The significant disparity in placental structure observed in this study between the LSES and HSES groups at a 
comparable gestational period is interesting and is suggestive of a predominant hypoxemic placental development under the stress of undernutrition. Further, the central disposition of blood vessels suggests immaturity of the floating villi which may be due to increased villous formation aimed at increasing nutrient transfer to the fetus from maternal circulation.

Further studies are needed with sufficient sample size at each gestational age in early pregnancy to determine the exact nature by which periconceptional nutritional status affects the development of placenta and implantation.

\section{AUTHORS' CONTRIBUTION}

Dr. J. J. Babu Geddam : Conducted the IHC, morphometry, data analysis and interpretation of results and writing of manuscript. Dr.Radhakrishna KV : Contribution of data analysis and interpretation of results. Dr.Ramalakshmi BA: Recruitment of subjects and gynaecological examination of subjects and collection of the placental samples. Dr. Quadri SSYH: Cross checking of IHC slides and quality control of staining. Dr. Sesikeran B: Study design, quality control of slides and guiding in writing of manuscript.

\section{ACKNOWLEDGMENTS}

We are thankful to Dr.B.Sivakumar, Former Director and Dr.P.Bhaskaram, Former Deputy Director (Sr.Gr.), National Institute of Nutrition, Hyderabad for their contribution to this project. We thank the staff of Niloufer Hospital for Women and Children, Hyderabad and Dr.Savita Devi, Chief Obstetrician and Gynecologist of Swapna Nursing Home, Hyderabad, India, for their assistance in this study. The technical assistance of Mr. B.N Goud, Mrs.Sharada, Mr.Ch.Hanumantha Reddy and Mr.A Kiran Kumar and secretarial assistance of Mrs.MaliniV.Rao are highly acknowledged.

\section{REFERENCES}

1. Ahmed A, Kilby MD (1997) :Hypoxia or Hyperoxia in placental insufficiency. Lancet 350, 826-827.

2. Anthony FW, Evans PW, Wheeler T, Wood PJ. (1997):Variation in detection of VEGF in maternal serum by immunoassay and the possible influence of binding proteins. Ann Clin Biochem 34,276-280.

3. Baker PN, Krasnow J, Roberts JM, Yeo KT. (1995): Elevated serum levels concentrations of VEGF in patients with pre eclampsia. Obst.Gynaecol. 86, 815-21.

4. Benersche K,Kufferman P, (1990): Pathology of human placenta. New York Springer-Verlog.

5. Bieri G, Tolliver JJ, Catignani GL, (1979): Simultaneous determination of alpha tocopherol and retinol in plasma or red cells by high pressure liquid chromatography. AJCN 32,2143-2149.
6. Charnock-Jones DS, Sharkey AM, Boocock CA et al. (1994): Vascular endothelial growth factor receptor localization and activation in human trophoblast and choriocarcinoma cells. Biol. Reprod. 51,524-530.

7. Cheung CY.(1997):VEGF possible role in fetal development and placental function. J Soc Gynecol Invest. 4,169-177.

8. Clark DE, Smith SK, Sharkey AM, Charnock-Jones DS et al. (1996): localization of VEGF and expression of its receptors Fit and Kdr in human placenta throughout pregnancy. Hum.Reproduction. 11,1090-1098.

9. de Onis M, Blossner M, Villar J. (1998): Levels and pattern of IUGR in developing countries .Eu .J Clin Nutr 52,S1, 5-15.

10. de Onis M,. Villar J, Gulmenzoglu M. (1998): Nutritional interventions to prevent IUGR. evidence from random controlled trails. Eur. J. Clin. Nutr. 52, Suppl, 1:S83-93.

11. Durnin JV, McKillop FM, Grant G, Fitzgerald G (1987): Energy requirements of pregnancy in Scotland. Lancet 8564, 897-900.

12. Evans PW, Wheeler T, Anthony FW, Osmond C. (1998): A longitudinal Study of maternal serum vasular endothelial growth factor in early pregnancy. Hum Reproduction 13, 1057-1062.

13. Genbacev O, Joslin R, Damsky CH, Polliotti BM, Fisher SJ. (1996): Hypoxia alters early gestation human cytotrophoblast differentation /invasion in vitro and models the placental defects that occur in pre eclampsia. $J$ Clin Invest 97,540-550.

14. Graham CH, Lala PK. (1992): Mechanisms of placental invasion of the uterus and their control. Biochem Cell Biol . 70, 867-874.

15. Husani MA,.Husani Y.K, Sandja DK, Jahari AB, Barizi, D Karayadi (1995): Maternal anthropometry and pregnancy outcomes in Indonesia. D. Karayadi. WHO Bullitein OMS: 73,:77-79.

16. Hustin J. Vascular physiology and pathophysiology of early pregnancy in: Bourne T,Jauniaux E,Jurkovic D, (1995): Editors. Trans vaginal colour doopler. Heidelberg:Springer-Verlag, 47-56.

17. INACG (1985) Measurement of iron status: A report of International Nutritional Anaemia Consultantive Group .

18. Jackson MR, Carney EW, Lye SJ et al. (1994): Localization of two angiogenic growth factors(PDECGF and VEGF) in human placenta throughout the gestation. Placenta. 15, 341-353.

19. Jaffe R, Warsof SL, (1992): Color Doppler imaging in the assessment of uteroplacental blood flow in abnormal first trimester intrauterine pregnancies:an attempt to define etiological mechanisms. J Ultrasound Med 11, 41-44.

20. James C.Cross,Zena W,Susan J.Fischere. (1994): Implantation and the placenta:Key picture of the development puzzle. Science. 266,1508-1518.

21. Jauniaux E, ,Jurkovic D,Gulbis B, Collins WP, Zaidi J, Campbell S. (1994): Investigation of the acid base balance of coelomic and amniotic fluids in early human pregnancy. Am J Obstet Gynecol 170,1365-1369.

22. Jauniaux E., Zaidi J, Jurkovic D, Campbells ,Hustin J. (1994) : Comparision of colour doppler features and pathological findings in the complicated early pregnancies. Hum. Reproduction 9,2432-2437.

23. Jelliffe DB. (1966) : Assessment of nutritional status of communities. WHO monograph series; WHO. No-53.

24. Kapur S, Kumar G, Mammen KC, Jesudian G (1971) Height and weight of South Indian women of child bearing age and their effect on birth weight and length of the baby. Ind. J. Med. Res. 57,1480-1490.

25. Kardjati S, Kusin JA, DC with C. (1988): Energy supplementation in the last trimester of pregnancy in East Java:1.Effect on birth weight. $\mathrm{Br} \mathrm{J}$ Obstet Gynaecol, 95,783-794.

26. Krammer M. (1987): Determinants of IUGR and gestational duration. Bull. World Health. Org., 663-737.

27. Kupferminc MJ, Daniel Y, Englender T, Baram A, Many A, Jaffa AJ et al. (1997): VEGF is increased in patients preeclampsia. Am J. Reprod Immunol, 38,302-306.

28. Kurjak A, Zalud I, Salihagic A, Crevenkovic G, Malajevic R. (1991):Trans vaginal colour doppler assessment of abnormal early pregnancy. J. Perinat. Med. 19,155-165.

29. Kusin JA, Kadjati S, Renquist UH (1994): Maternal body mass index : The functional significance during reproduction. E J C N 48 (Suppl.3), S56-S57.

30. Lala PK, Hamiliton GS. (1996): Growth factors proteases and protease inhibitors in the maternal fetal dialogue. Placenta 17,545-555. 
31. Lyall F, Greer IA, Boswell F, Fleming R. (1997): Suppression of plasma VEGF immunorectivity in normal pregnancy and in preeclampsia. Br J Obstet Gynaecol, 104,223-228.

32. Lyall F,.Greer IA, Boswell F, Fleming R. (1997): Suppression of serum VEGF immunoreactivity in normal pregnancy and in pre eclampsia. Br J Obs Gynaec 104, 223-228.

33. Meegdes, H.L.M.,Ingenhoes, R.,Peeters, LLH. And Exalto,N. (1988): Early pregnancy wastage :Relationship between chrionic vascularization and embrynic development. Fertil. Steril. 49,216-220.

34. Meuris S, Nagy AM, Delogene-Desnoeck J, Jurkvic D, Jauniaux E. (1995):Temporal relationship between the human coronic gonodotrophin peak and the establishment of intervillous blood flow in early pregnancy peak. Hum Reproduction 19, 947-950

35. Nadamuni Naidu A, Pralhad Rao N. (1994): Body mass index : A measure of the nutritional status in Indian population. E J C N 48: (Suppl 3), S131-S140.

36. Naeye RL (1979): weight gain and the outcome of pregnancy. Am J Obstet Gynaecol 135, 3-9.

37. Rodesch F, Simon P, Donner C, Jauniaux E. (1992): Oxygen measurements in the endometrial and trophoblastic tissues during early pregnancy. Obste. Gynecol 80, 283-285.
38. Scheweiki D, Itin A, Soffer D et al. (1992): Vascular endothelial growth factor induced by hypoxia may mediate hypoxia initiated angiogenesis. Nature 359, 843-845.

39. Sharkey AM, Cooper JC, .Banforth Jr, Mclaren J, Clark DE, Charnok-Jones DS. et al. (1996): Maternal plasma levels of VEGF in normotensive pregnancy and pregnancies complicated by pre-eclampsia. Eur J Clin Invest 26,(12)1182-1185.

40. Taylor A, Bryant TN (1981): Comparison of procedures for determination of copper and zinc in serum by Atomic Absorption Spectroscopy. Clin Chim Acta 110, 83-90

41. te Velde EA, Exalto N, Hesseling P, Van der Linden HC. (1997): First trimester development of human chorionic villous vascularization studied with CD 34 Immunohistochemistry Hum Reprod 12, 1377-1381.

42. Torry DS, Torry RJ. (1997): Angiogenesis and the expression of VEGF in endometium and placenta. Am J Reproduct Immunol. 37,21-29.

43. Villar J, de Onis M, Kestler E, Bolanos F, Cerezo R, Berndes H. (1990): The differential neonatal morbidity of the IUGR syndrome. Am J Obstet Gynecol 163, 151-157.

44. Wheeler T, Elcock,CL, Anthony FW. (1995):Angiogenesis and the placental environment. Placenta 16, 289-296. 